\title{
Preparation of curcumin-loaded nanoparticles and determination of the antioxidant potential of curcumin after encapsulation
}

\author{
Rosana Aparecida da Silva-Buzanello', Mateus Ferreira de Souza², Daniela Alves de Oliveira², \\ Evandro Bona ${ }^{1}$, Fernanda Vitória Leimann ${ }^{1}$, Lúcio Cardozo Filho ${ }^{4}$, Pedro Henrique Hermes de Araújo ${ }^{3}$, \\ Sandra Regina Salvador Ferreira ${ }^{3}$ and Odinei Hess Gonçalves ${ }^{1 *}$ \\ 1Post-graduation Program of Food Technology - PPGTA, Universidade Tecnológica Federal do Paraná - \\ UTFPR, Campo Mourão, PR, Brazil \\ ${ }^{2}$ Food Technology and Engineering Department - DALIM, Universidade Tecnológica Federal do Paraná - \\ UTFPR, Campo Mourão, PR, Brazil \\ ${ }^{3}$ Department of Chemical and Food Engineering - EQA, Universidade Federal de Santa Catarina - UFSC, \\ Florianópolis, SC, Brazil \\ ${ }^{4}$ Department of Chemical Engineering, Universidade Estadual de Maringá - UEM, Maringá, PR, Brazil \\ *odinei@utfpr.edu.br
}

\begin{abstract}
Encapsulation of bioactive compounds has been carried out to improve bioavailability and to protect them against harm conditions. However, encapsulation processes are often aggressive and it is important that encapsulated substances keep their biological activity. In this work curcumin was nanoencapsulated using dichloromethane as solvent and ultrasound as dispersion device. Nanoparticles were obtained using different curcumin concentrations and encapsulants (PLLA and Eudragit S100) and the encapsulation efficiency was inferred using spectroscopic and calorimetric techniques as well as optical microscopy. Total phenolic contents and antioxidant activity tests were applied to the curcumin before and after encapsulation and also to blank polymer nanoparticles. Results demonstrated that the encapsulation process had no deleterious influence on its antioxidant activity.
\end{abstract}

Keywords: curcumin, antioxidant potential, nanoencapsulation, miniemulsification.

\section{Introduction}

Curcumin has attracted much attention due to its significant medicinal potential ${ }^{[1-4]}$. Industry is also interested in curcumin since its antioxidant properties were demonstrated using a number of different methods ${ }^{[3]}$. Eybl et al.$^{[5]}$ demonstrated that curcumin protects against lipid peroxidation induced by cadmium, which is a highly carcinogenic compound. The contribution of each part of the curcumin molecule for the whole antioxidant activity has been subject of some debate ${ }^{[6,7]}$. Galano et al. ${ }^{[8]}$ shed light on the apparent contradictions among the antioxidant mechanisms proposed by different authors. They claimed that the predominant mechanism depends on the electron withdrawing character of the free radical itself and also on the solvent polarity. Feng and $\mathrm{Liu}^{[9]}$ concluded that curcumin acts as an antioxidant mainly through the phenolic hydroxyl group.

Despite its biological properties, large scale use of curcumin by pharmaceutical and food industry has been hindered by its low water solubility and its instability in the presence of light, excessive heat, alkaline conditions, metallic ions and others ${ }^{[10]}$. Micro and nanoencapsulation have been investigating as a feasible way to protect and to stabilize curcumin until it reaches its destination into the body or to increase its bioavailability ${ }^{[11]}$. Miniemulsification or emulsification followed by solvent evaporation are suitable techniques to obtain nano or microparticles, respectively ${ }^{[12]}$. Biocompatible polymers are of interest because they can be readily shaped in submicrometric particles allowing them to carry the encapsulated compound to specific sites inside the body. Recent works demonstrated that curcumin concentration inside nanoparticles can be readily determined by simple methods with the necessary accuracy ${ }^{[13]}$. However, miniemulsification and emulsification require the use of organic solvents, which is in direct contact with the encapsulated compounds. In the case of curcumin, it is necessary to investigate if decomposition or chemical modifications occurs during the particles production since biological activity is closely related to the molecular structure ${ }^{[8]}$. In miniemulsification, there is also the need of intense energy to break up the dispersed phase (either organic or aqueous) to achieve submicrometric sizes. The most common devices are high pressure homogenizators and high potency ultrasound devices. Despite the usually low dispersion times required to obtain polymer nanoparticles, there is the need to investigate if the encapsulated compound remains unchanged after the encapsulation process. The objective of this work was to investigate the antioxidant activity of curcumin after its encapsulation on polymer particles by miniemulsification-solvent evaporation technique. 
The encapsulation process was investigated in respect of different encapsulants in order to determine the encapsulation efficiency and final particles morphology. Finally, total phenolic content (Folin-Ciocalteau colorimetric method) and the antioxidant activity of curcumin before and after the encapsulation were determined by ABTS and $\beta$-carotene bleaching method.

\section{Materials and Methods}

\subsection{Materials}

Folin-Ciocalteau phenol reagent, gallic acid, ABTS [2,2_-azino-bis-(3-ethylbenzothiazoline-6-sulfonic acid)], Trolox and curcumin $(99.5 \%)$ were obtained from Sigma-Aldrich. Lecithin (Alfa Aesar) was used as surfactant. Methanol (Vetec, 99.8\%) and dichloromethane (Vetec, 99.5\%) were used in the encapsulation efficiency determination. Distilled water was used as continuous phase in the miniemulsion preparation.

Poly(L-lactic acid) (PLLA, 4,000 g/gmol) was obtained by L-lactide ring opening polymerization (tinII-octanoate $0.01 \mathrm{wt} \%, 120^{\circ} \mathrm{C}, 24$ hours, Bendix $\left.{ }^{[14]}\right)$ and used as encapsulant. Poly(methacylic acid-co-methyl methacrylate) (Eudragit S100, 125,000 g/gmol, Evonik Industries AG) was also used as encapsulant. All chemicals were used as received without further purification.

\subsection{Nanoparticle preparation}

Curcumin loaded nanoparticles were obtained using the miniemulsification-evaporation technique as described by Leimann et al. ${ }^{[15]}$ with some modifications. The procedure varied depending on the encapsulant used as described below. The formulation used was $22.400 \mathrm{~g}$ water, $0.180 \mathrm{~g}$ lecithin, $11.500 \mathrm{~g}$ dichloromethane, and $0.390 \mathrm{~g}$ encapsulant (PLLA and Eudragit S100 or a mixture of them). No co-stabilizer was used since it is known that preformed polymers are effective in preventing emulsion degradation by diffusion ${ }^{[16]}$.

When PLLA was used as encapsulant, PLLA and lecithin were dissolved in dichloromethane for 10 minutes and, after this, curcumin was added and mixed for $5 \mathrm{~min}$ $(1,3,6,18 \mathrm{wt} \%$ of the total encapsulant mass). This solution was added to the distilled water under gentle stirring. The macroemulsion formed was sonicated (Fisher-Scientific, Ultrasonic Dismembrator 120 W, 1/8" tip) for 180 seconds in a pulse regime (30 s sonication, $10 \mathrm{~s}$ pause) and the solvent was evaporated for 18 hours at $40^{\circ} \mathrm{C}$. When PLLA and Eudragit S100 together were used as encapsulant, Eudragit S100 was dissolved in dichloromethane at $60{ }^{\circ} \mathrm{C}$ for 20 minutes. After this, the mixture was cooled and the evaporated solvent was added again. From this point, steps were the same as described above.

\subsection{Characterization}

The actual concentration of curcumin $\left([\mathrm{cur}]_{\text {actual }}\right)$ in the final nanoparticles dispersion (encapsulated and non-encapsulated) was determined as follows. A nanoparticle dispersion sample ( $1 \mathrm{~mL}$ ) was dried at $70^{\circ} \mathrm{C}$ for 2 hours in a circulation oven and then diluted in $1 \mathrm{~mL}$ of dichloromethane. The polymer was precipitated by adding $1 \mathrm{~mL}$ of cold methanol, filtered
(Millipore $0.45 \mu \mathrm{m}$ ) and diluted in methanol/dichloromethane $1: 1(\mathrm{vol} / \mathrm{vol})$ to $25 \mathrm{~mL}$. Absorbance was measured at $465 \mathrm{~nm}$ (OceanOptics, UV650). The concentration of curcumin effectively encapsulated in the nanoparticles was determined as follows. A nanoparticle dispersion sample $(5 \mathrm{~mL})$ was centrifugated at $1,000 \mathrm{rpm}$ for 10 minutes in order to precipitate the non-encapsulated curcumin crystals. $1 \mathrm{~mL}$ of the supernatant was dried at $70^{\circ} \mathrm{C}$ for 2 hours in a circulation oven and then diluted in $1 \mathrm{~mL}$ dicholromethane. The polymer was precipitated by adding $1 \mathrm{~mL}$ of cold methanol, filtered (Millipore $0.45 \mu \mathrm{m}$ ) and diluted in methanol/dichloromethane $1: 1(\mathrm{vol} / \mathrm{vol})$ to $25 \mathrm{~mL}$. Absorbances were measured at $465 \mathrm{~nm}$ and encapsulation efficiency was calculated using Equation 1. This method was validated elsewhere in respect of linearity, precision and accuracy ${ }^{[13]}$.

$$
\operatorname{EE}(\%)=\frac{[\text { cur }]_{\text {encapsulated }}}{[\text { cur }]_{\text {actual }}} * 100
$$

Average molar masses of PLLA were determined by Gel Permeation Chromatography (GPC) using polystyrene standards ( 580 to $3,800,000 \mathrm{~g} / \mathrm{mol}$ ) and tetrahydrofuran as eluent at $1 \mathrm{~mL} / \mathrm{min}$. The following apparatus was used: Shimadzu model LC-20A, with a refraction index detector RID-10A, automatic injector SIL-20A, oven CTO-20A and three columns $(0.8 \times 30 \mathrm{~cm}, \mathrm{GPC}-801$, GPC-804 and GPC-807). The samples were dissolved in tetrahydrofuran (THF, Sigma-Aldrich) at approximately $7.0 \mathrm{mg} \cdot \mathrm{ml}^{-1}$, filtered through a $0.45 \mu \mathrm{m}$ Nylon filter then analyzed at $35^{\circ} \mathrm{C}$.

Average particles size $\left(\mathrm{D}_{\mathrm{z}}\right)$ and polydispersion index (PDI) were determined by Dynamic Light Scattering (DLS, Malvern Zetasizer - Nano Series) using backscattering detection $\left(173^{\circ}\right)$ in samples without previous dilution. PDI was calculated using the standard deviation $(\sigma)$ of the size distribution by Equation 2.

$$
P D I=\frac{\sigma^{2}}{D_{z}^{2}}
$$

Particle morphology was investigated by Transmission Electron Microscopy (TEM, Jeol JEM 1011 at 100kV). Samples were carefully placed on 300 mesh parlodium-coated cooper TEM grids and stained using osmium tetroxide for 4 hours. The presence of free curcumin crystals in the nanoparticles latex was investigated by optical microscopy (BIOVAL, L2000A). Infrared spectroscopy analysis of PLLA, Eudragit S100, lecithin, curcumin and the curcumin-loaded nanoparticles were carried out using a Frontier PerkinElmer FTIR-UATR with $4 \mathrm{~cm}^{-1}$ resolution and peak normalization. Differential scanning calorimetry (DSC) of the lyophilized nanoparticles samples were performed using a Simultaneous Thermal Analysis calorimeter (Perkin Elmer STA 6000) from 20 to $390^{\circ} \mathrm{C}$ at $10^{\circ} \mathrm{C} / \mathrm{min}$ and nitrogen at $30 \mathrm{~mL} / \mathrm{min}$. Polymer crystallinity $\left(x_{c}\right)$ was calculated using Equation 3. Here, $\Delta \mathrm{H}_{\mathrm{m}}$ is the specific enthalpy of melting and $\Delta \mathrm{H}_{\mathrm{m}}^{\mathrm{c}}$ is the specific enthalpy of melting of a $100 \%$ crystallinity sample $(93.7 \mathrm{~J} / \mathrm{g} \text { for PLLA })^{[17]}$ and $\varphi$ is the mass fraction of PLLA in the blend nanoparticles.

$$
\chi_{c}(\%)=\frac{1}{\varphi} \frac{\Delta H_{m}}{\Delta H_{m}^{c}} \times 100
$$




\subsection{Total phenolic content}

The total phenolic content (TPC) was determined according to the Folin-Ciocalteu method ${ }^{[18]}$. The reaction mixture was composed of $0.1 \mathrm{~mL}$ of extracts solutions (concentration of $1,667 \mathrm{mg} / \mathrm{L}), 7.9 \mathrm{~mL}$ of distilled water, $0.5 \mathrm{~mL}$ of Folin-Ciocalteu reagent (a mixture of phosphomolybdate and phosphotungstate) and $1.5 \mathrm{~mL}$ of $20 \%$ sodium carbonate, placed in amber flasks. The flasks were agitated and allowed to stand for $2 \mathrm{~h}$ and the absorbance was measured at $765 \mathrm{~nm}$. Results (mean value of the triplicate assays) were expressed as milligrams of gallic acid equivalents per gram of the extract (mg GAE/g) using a gallic acid standard curve (concentration range was 0 to $500 \mathrm{mg} / \mathrm{mL}, \mathrm{R}^{2}=0.9969$ ).

\subsection{Antioxidant potential}

$\mathrm{ABTS}^{\cdot+}$ radical scavenging assay was carried out based on the procedure described by Re et al. ${ }^{[19]}$ using the synthetic vitamin $\mathrm{E}$ dissolved in ethanol, Trolox (6-hydroxy-2,5,7,8 -tetramethylchroman-2-carboxylic acid) (Sigma-Aldrich Co, St. Louis, USA), as an antioxidant standard. ABTS [2,2 -azino-bis-(3-ethylbenzotiazoline-6-sulfonic acid)] was dissolved in water to a concentration of $7.0 \mathrm{mM}$, and submitted to reaction with $2.45 \mathrm{mM}$ of potassium persulfate for the formation of the radical $\mathrm{ABTS}^{-+}$, that is reduced in the presence of an antioxidant compound hydrogen donor. The absorbance was measured at $754 \mathrm{~nm} 6$ min after the initial mixing of the samples and standard with the ABTS solution. Results were expressed as Trolox equivalent antioxidant capacity (TEAC) ( $\mathrm{mM}$ concentration of a Trolox solution whose antioxidant activity is equivalent to the activity of $1.0 \mathrm{mg} / \mathrm{mL}$ of sample solution). In order to find TEAC values, a separate concentration response curve for standard Trolox solutions was prepared.

The antioxidant activity from the $\beta$-carotene/linoleic acid system ( $\beta$-carotene bleaching method) was carried out according to the method described by Matthäus ${ }^{[20]}$. Briefly, an aliquot of $5 \mathrm{~mL}$ of a stable emulsion of $\beta$-carotene/linoleic acid (40 g of linoleic acid, $400 \mathrm{mg}$ of Tween-20 and $3.34 \mathrm{mg}$ of $\beta$-carotene $/ 100 \mathrm{ml}$ distilled water) was added with $0.2 \mathrm{~mL}$ of the extract solutions (1667 $\mathrm{mg}$ curcumin/mL) and the absorbance was immediately measured at $470 \mathrm{~nm}$ against a blank consisting of the emulsion without $\beta$-carotene. The tubes were placed in a water bath at $50{ }^{\circ} \mathrm{C}$ and the absorbance was measured every $15 \mathrm{~min}$ up to $120 \mathrm{~min}$. The $\beta$-carotene bleaching rate was determined by the difference in absorbance (at $470 \mathrm{~nm}$ ) values at $0 \mathrm{~min}$ and at $120 \mathrm{~min}$ (mean of the triplicate experiments) and converted into percentage of antioxidant activity ( $\% \mathrm{AA})$.

\section{Results and Discussion}

\subsection{Influence of curcumin concentration}

Table 1 presents the average particles size, polydispersion index and curcumin encapsulation efficiency for different curcumin concentrations (PLLA as encapsulant). Average particles size, polydispersion index and curcumin encapsulation efficiency for different encapsulants ( $3 \mathrm{wt} \%$ added curcumin) are presented in Table 2. Figure 1 presents an image of the latex obtained with $12 \mathrm{wt} \%$ curcumin.
Table 1. Diameter average particles (Dz), polydispersion index (PDI), curcumin encapsulation efficiency (EE\%) for different curcumin concentration.

\begin{tabular}{cccc}
\hline $\begin{array}{c}\text { Added } \\
\text { curcumin } \\
(\mathbf{w t} \%)\end{array}$ & $\mathbf{D}_{\mathbf{z}} \mathbf{( n m )}$ & PDI (-) & EE (\%)* \\
\hline 0 & $187 \pm 6$ & $0.223 \pm 0.004$ & - \\
1 & $184 \pm 4$ & $0.195 \pm 0.005$ & $96.6 \pm 3.4^{\mathrm{a}}$ \\
3 & $171 \pm 8$ & $0.170 \pm 0.034$ & $95.8 \pm 1.0^{\mathrm{a}}$ \\
6 & $177 \pm 6$ & $0.160 \pm 0.014$ & $77.9 \pm 5.6^{\mathrm{b}}$ \\
12 & $187 \pm 3$ & $0.216 \pm 0.009$ & $30.2 \pm 0.5^{\mathrm{c}}$ \\
$p$ (ANOVA) & 0.123 & 0.0514 & 0.0000 \\
\hline
\end{tabular}

*Different letters in the same row indicate statistical differences $(\mathrm{p}<0.05)$.

Table 2. Diameter average particles (Dz), polydispersion index (PDI), curcumin encapsulation efficiency (EE\%) for different encapsulants ( $3 \mathrm{wt} \%$ curcumin).

\begin{tabular}{cccc}
\hline $\begin{array}{c}\text { Encapsulants } \\
\text { (w:w) }\end{array}$ & D $_{\mathbf{z}}(\mathbf{n m})^{*}$ & PDI (-) & EE (\%)* \\
E S100: PLLA & & & \\
\hline $0: 1$ & $171 \pm 8^{\mathrm{a}}$ & $0.170 \pm 0.034$ & $95.8 \pm 1.0^{\mathrm{a}}$ \\
$1: 1$ & $195 \pm 9^{\mathrm{a}}$ & $0.235 \pm 0.023$ & $43.9 \pm 1.4^{\mathrm{b}}$ \\
$1: 0$ & $232 \pm 9^{\mathrm{b}}$ & $0.235 \pm 0.018$ & $34.5 \pm 1.0^{\mathrm{c}}$ \\
$p$ (ANOVA) & 0.0060 & 0.1810 & 0.0004 \\
\hline
\end{tabular}

*Different letters in the same row indicate statistical differences $(\mathrm{p}>0.05)$.

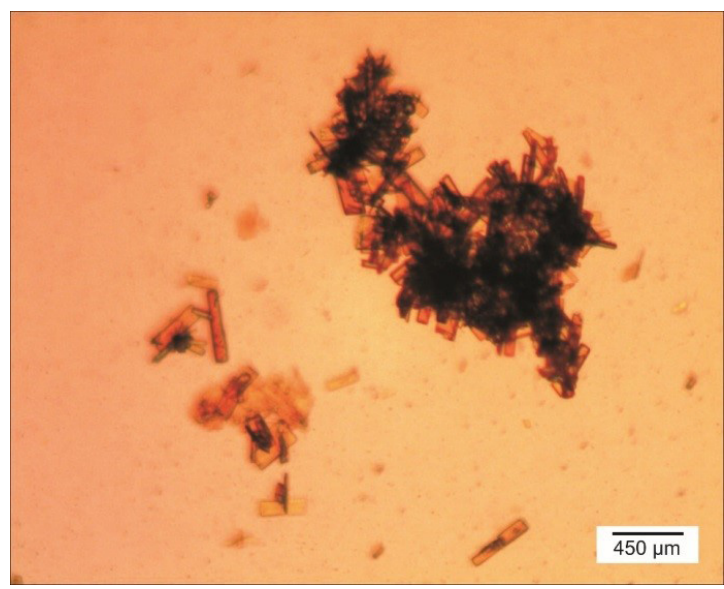

Figure 1. Optical microscope images of the curcumin-loaded PLLA latex (12 $\mathrm{wt} \%$ curcumin).

Average nanoparticles diameter and polydispersity was not significantly influenced by curcumin $(p>0.05)$ meaning that the concentrations used were not high enough to affect the equilibrium between breakage and coalescence of the solvent/polymer/curcumin droplets during ultrasound application. This also means that the differences found in the encapsulation efficiency were solely due to the amount of curcumin added initially. Efficiency was high when low concentration of curcumin was used ( 1 and $3 \mathrm{wt} \%$ ) but it drastically decreased for higher amounts (6 and $12 \mathrm{wt} \%$ ). 
Free curcumin crystals were easily found in the latex when $12 \mathrm{wt} \%$ curcumin was added, meaning that part of the total curcumin was not effectively encapsulated in the nanoparticles. This is in agreement with the encapsulation efficiency values determined by UV-Vis (Table 1). It worth noting that no curcumin macroscopic crystals could be found in the latex when $3 \mathrm{wt} \%$ curcumin was added. This behavior was also found by other authors when encapsulating curcumin in yeast cells of Saccharomyces cerevisiae by a diffusion method ${ }^{[21]}$. The same occurred in the case of spray drying encapsulation using porous starch and gelatin as encapsulants ${ }^{[2]}$ and anti-solvent precipitation using zein as encapsulant ${ }^{[23]}$. Results indicate that there is a maximum amount of curcumin that can be encapsulated and the excess is removed from the dichloromethane-PLLA system during the solvent evaporation step forming the micrometric crystals observed in Figure 1.

Although there was difference in the particles diameter for different encapsulant composition, this could not account to the high decrease in the encapsulation efficiency observed when Eudragit S100 was used as encapsulant. This could be attributed to the higher hydrophilicity of the methacrylic acid groups of Eudragit S100 leading to less affinity with curcumin.

\subsection{Nanoparticles characterization}

Figure 2 presents thermograms of pure curcumin, pure PLLA, pure Eudragit S100 as well as curcumin-loaded (3 wt\%) PLLA, Eudragit S100 and PLLA/Eudragit S100 blend nanoparticles. In Table 3 the glass transition temperatures and PLLA crystallinity are presented.

Melting temperature $\left(\mathrm{T}_{\mathrm{m}}\right)$ of curcumin was found to be $171{ }^{\circ} \mathrm{C}$ as indicated by the dashed line in Figure 2 which is in accordance with values presented in literature ${ }^{[24-26]}$. Glass transition temperature ( $\mathrm{T}_{\mathrm{q}}$ ) of PLLA nanoparticles can be observed at $60{ }^{\circ} \mathrm{C}$ as a relaxation peak due to its thermal history. Eudragit $\mathrm{S} 100$ presented $\mathrm{T}_{\mathrm{g}}$ and $\mathrm{T}_{\mathrm{m}}$ at $160{ }^{\circ} \mathrm{C}$ and $180^{\circ} \mathrm{C}$, respectively, the same values reported elsewhere ${ }^{[27]}$. In curcumin-loaded nanoparticles the melting peak of curcumin could not be detected. This behavior was also found by other authors ${ }^{[24-26]}$ and can be attributed to the fact that curcumin was successfully encapsulated in the nanoparticles forming a solid solution evidencing the strong interactions between the encapsulants and curcumin.

PLLA powder presented high crystallinity which decreased after the nanoparticles production (from $72 \%$ to $48 \%$ ) meaning that solvent evaporation was slow enough to allow polymer chains conformation in the amorphous phase. PLLA crystallinity further decreased due to the presence of curcumin, indicating that it might be entrapped inside the nanoparticles hindering the formation of the PLLA crystalline phase.

In the PLLA/Eudragit S100 blend nanoparticles it is possible to observe two separated glass transition: one around $60^{\circ} \mathrm{C}$ for PLLA and other around $160^{\circ} \mathrm{C}$ for Eudragit S100. PLLA and Eudragit pure nanoparticles presented the same transition temperatures which is a strong indication that some degree of polymer separation took place ${ }^{[28]}$.

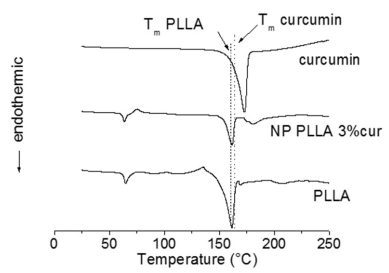

(a) PLLA blank, curcumin-loaded nanoparticles (3\%wt) and free curcumin

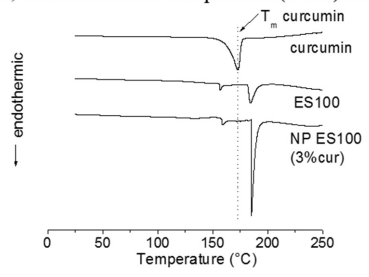

(b) Eudragit S100 blank, curcumin-loaded nanoparticles (3\%wt) and free curcumin.

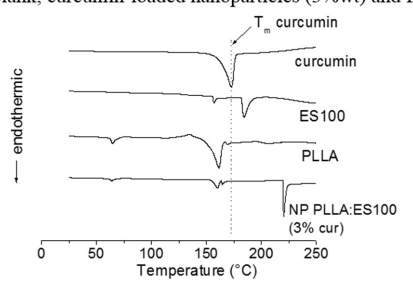

(c) PLLA, Eudragit S100, free curcumin and curcumin-loaded PLLA/Eudragit S100

$$
\text { nanoparticles. }
$$

Figure 2. Thermograms of blank and curcumin-loaded nanoparticles.

Table 3. Melting temperatures and PLLA crystallinity.

\begin{tabular}{cccc}
\hline Experimental condition & $\mathbf{T m}\left({ }^{\circ} \mathbf{C}\right)$ & $\begin{array}{c}\Delta \mathbf{H m} \\
(\mathbf{J} / \mathbf{g})\end{array}$ & $\boldsymbol{x}_{\mathbf{c}}(\%)$ \\
\hline $\begin{array}{c}\text { PLLA } \\
\text { Blank PLLA nanoparticles } \\
\quad \text { (no curcumin) }\end{array}$ & 167 & 67.5 & 72 \\
$\begin{array}{c}\text { Curcumin-loaded PLLA } \\
\text { nanoparticles (1\%wt cur) } \\
\text { Curcumin-loaded PLLA }\end{array}$ & 154 & 45.3 & 48 \\
$\begin{array}{c}\text { nanoparticles (3\%wt cur) } \\
\text { Curcumin-loaded } \\
\text { Eudragit S100/PLLA } \\
\text { nanoparticles(3\%wt cur) }\end{array}$ & 161 & 26.9 & 29 \\
\hline * Considering PLLA:Eudragit S100 mass proportion in the \\
nanoparticles (1:1w/w).
\end{tabular}

Figure 3 shows the FTIR spectra of blank PLLA nanoparticles (without curcumin), pure curcumin and the curcumin loaded-nanoparticles (3 wt $\%$ ).

Curcumin is often identified by its phenolic absorption band at $3508 \mathrm{~cm}^{-1[10,25]}$. Other curcumin characteristic bands can also be seen such as the aromatic C-C band $\left(1602 \mathrm{~cm}^{-1}\right)$, olefinic C-H $\left(1428 \mathrm{~cm}^{-1}\right)$, asymmetric C-O-C $\left(1026 \mathrm{~cm}^{-1}\right)$ and phenolic C-O $\left(1276 \mathrm{~cm}^{-1}\right)$. PLLA(C-H at 1450 and $1360 \mathrm{~cm}^{-1}$, asymmetric $\mathrm{C}-\mathrm{O}$ at $1130 \mathrm{~cm}^{-1}, \mathrm{C}=\mathrm{O}$ at $1760 \mathrm{~cm}^{-1}$ ), lecithin (R-O-P-O-R' stretching band at $1055 \mathrm{~cm}^{-1}$ ) and Eudragit 


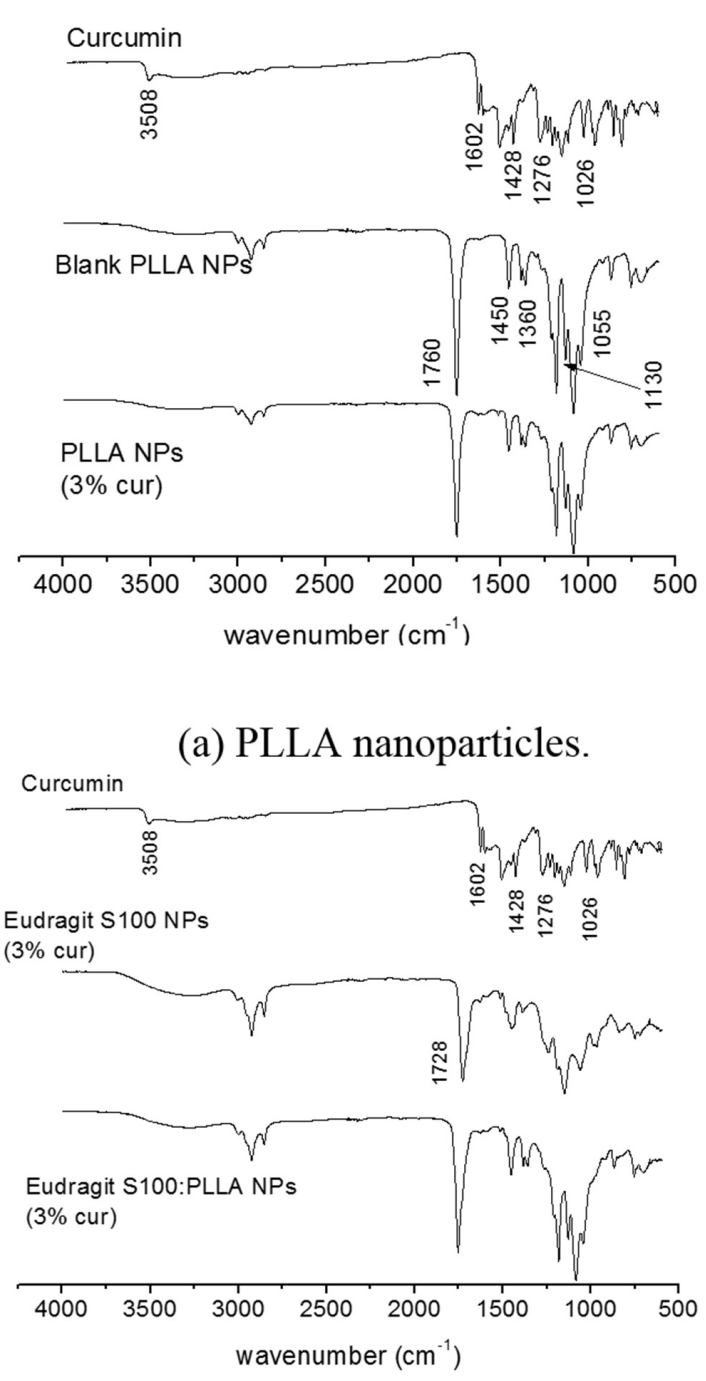

(b) Eugradit S100 nanopaticles.

Figure 3. FTIR spectra of pure curcumin, blank PLLA nanoparticles and curcumin-loaded nanoparticles.

S100 absorption bands (carboxyl ester at $1728 \mathrm{~cm}^{-1}$ ) can also be found ${ }^{[10,29,30]}$ (all absorption bands are indicated in Figure 3). Curcumin phenolic band was attenuated in the nanoparticles when comparing to pure curcumin suggesting that it was located inside the nanoparticles. This can also be attributed to the interaction between curcumin and the encapsulants mostly through hydrogen bonding.

Transmission electron microscopy image of PLLA nanoparticles and PLLA:Eudragit S100 (1:1) nanoparticles are presented in Figure 4 ( $3 \mathrm{wt} \%$ curcumin).

Curcumin-loaded PLLA nanoparticles appeared as homogeneous nanospheres with diameters around $200 \mathrm{~nm}$ corroborating the DLS results. On the other hand, PLLA/Eudragit S100 blend nanoparticles presented phase separation morphology in accordance with the DSC results. PLLA can be seen as light gray and Eudragit S100 as black due to differences in contrast under the electron

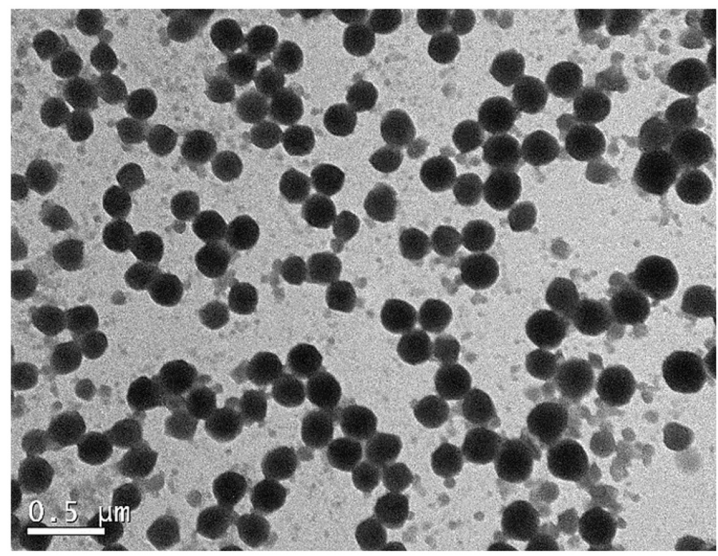

(a) PLLA nanoparticles.

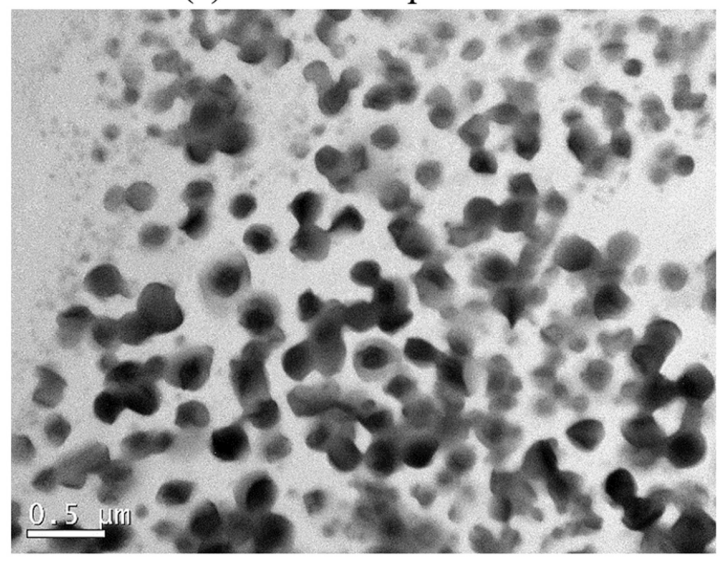

(b) PLLA:Eudragit S100 (1:1) nanoparticles.

Figure 4. Transmission Electron Microscopy of the curcumin-loaded nanoparticles ( $3 \% \mathrm{wt}$ curcumin).

beam, indicating that the more hydrophilic PLLA formed an outer shell and Eudragit S100 in the particles core as demonstrated in other works ${ }^{[31]}$. This core-shell morphology is also supported by the fact that, depending on the process kinetic, the semi-crystalline structure of PLLA could act as a driving force for phase separation ${ }^{[32]}$. It is worth noting that in both cases no free curcumin crystals could be found corroborating the encapsulation values found (Table 2).

\subsection{Antioxidant activity}

Table 4 presents the antioxidant activity of free curcumin, blank and curcumin-loaded nanoparticles.

Free and encapsulated curcumin presented high phenolic content (in gallic acid equivalents) and antioxidant activity, being effective ABTS scavenging and inhibitor of lipid peroxidation of linoleic acid emulsion. Literature reports that curcumin is an extremely potent lipid-soluble antioxidant proved by different methods including scavenging of a variety of radicals and inhibition of lipid peroxidation ${ }^{[3,33,34]}$. Phenolic antioxidants usually scavenge free radicals by an electron-transfer mechanism and curcumin acts as an extraordinarily potent $\mathrm{H}$-atom donor in neutral and acidic 
Table 4. Antioxidant activity of free curcumin, blank and curcumin-loaded nanoparticles.

\begin{tabular}{|c|c|c|c|c|}
\hline \multirow[b]{2}{*}{ Sample } & \multirow{2}{*}{$\begin{array}{l}\text { Total phenolic } \\
\text { content (TPC) } \\
\left(\mathrm{mg}_{\mathrm{GAE}} / \mathrm{g}_{\text {extract }}\right)\end{array}$} & \multicolumn{2}{|c|}{ ABTS } & \multirow{2}{*}{$\begin{array}{c}\beta \text {-caroten/linoleic acid } \\
\text { \%AA (after } 120 \text { min) }\end{array}$} \\
\hline & & $\%$ inhibition* & TEAC $\left(\mu \mathrm{M} / \mathrm{g}_{\text {extract }}\right)$ & \\
\hline Free curcumin & $495 \pm 8$ & $61 \pm 1$ & $824 \pm 5$ & $89 \pm 1$ \\
\hline $\begin{array}{c}\text { PLLA NPs } \\
\text { (3 wt } \% \text { curcumin })\end{array}$ & $604 \pm 27$ & $68 \pm 1$ & $906 \pm 6$ & $101 \pm 1$ \\
\hline $\begin{array}{l}\text { Blank PLLA NPs } \\
\text { (no curcumin) }\end{array}$ & $167 \pm 1$ & $5 \pm 1$ & $40 \pm 1$ & $16 \pm 1$ \\
\hline $\begin{array}{c}\text { Eudragit NPs } \\
(3 \mathrm{wt} \% \text { curcumin })\end{array}$ & $517 \pm 9$ & $77 \pm 3$ & $1063 \pm 9$ & $93 \pm 2$ \\
\hline $\begin{array}{l}\text { Blank Eudragit NPs } \\
\text { (no curcumin) }\end{array}$ & $55 \pm 4$ & $7 \pm 1$ & $72 \pm 6$ & $6 \pm 0$ \\
\hline
\end{tabular}

$\mathrm{GAE}=$ gallic acid equivalent; TEAC $=$ Trolox equivalent antioxidant activity. $* 100 \mu \mathrm{g}$ curcumin $/ \mathrm{mL}$ solution. $\ddagger 167 \mu \mathrm{g}$ curcumin $/ \mathrm{mL}$ solution.

aqueous solutions ${ }^{[35]}$. Ak and Gülçin ${ }^{[3]}$ demonstrated the electron donor capacity of curcumin for neutralizing free radicals by forming stable products, which property is associated with antioxidant activity ${ }^{[3]}$. Antioxidant capacity is widely used as a parameter for medicinal bioactive components since the reduction of inflammatory responses, chronic diseases, DNA damage, mutagenesis, carcinogenesis and inhibition of pathogenic bacterial growth is often associated with the termination of free radical propagation in biological systems ${ }^{[36]}$. Besides, lipid peroxidation consists of a series of free radical mediated chain reaction processes and is associated with several types of biological damage; therefore, quench those free radicals to terminate the peroxidation chain reactions can improve the quality and stability of food products ${ }^{[3]}$.

Blank nanoparticles (PLLA and Eudragit S100) also presented small antioxidant activity. This may be attributed to lecithin which can act as an oxidative stabilizer. Pan et al. ${ }^{[37]}$ demonstrated that lecithin can decrease the rate of oxidation of encapsulated curcumin in lecithin stabilized emulsions. In order to normalize the results presented on Table 4 and to allow a fair comparison, the amount of curcumin used in the antioxidant assays ("free curcumin") was equal to the mass of curcumin actually present in the nanoparticles. This explain the fact that the loaded nanoparticles presented slightly higher values of antioxidant activity than pure curcumin.

It is worth noting that curcumin was extracted from the particles before the antioxidant activity determination simulating the case in which curcumin is released from the nanoparticles. This methodology was also implemented by Wang et al. ${ }^{[38]}$ to determine the antimicrobial activity of encapsulated curcumin. Results indicated that curcumin kept its antioxidant properties after the encapsulation procedure meaning that the aggressive encapsulation conditions (ultrasound and solvent exposure) did not affect curcumin activity expanding its application also in aqueous systems.

\section{Conclusions}

Curcumin-loaded nanoparticles were obtained with different curcumin concentration and encapsulants. For PLLA nanoparticles, curcumin was not efficiently encapsulated when more than $3 \mathrm{wt} \%$ was added leading to the formation of free microscopic curcumin crystals. For this concentration, differential scanning calorimetry (DSC) and infrared spectroscopy (FTIR) indicated that curcumin was effectively encapsulated forming an amorphous dispersion inside the particle matrix. The same occurred when Eudragit S100 was the encapsulant. When PLLA and Eudragit S100 was used to form blend curcumin-loaded nanoparticles, Transmission Electron Microscopy along with DSC and FTIR strongly suggested that phase separation took place. The antioxidant activity of free curcumin was compared to the activity of encapsulated curcumin. ABTS, $\beta$-carotene and total phenolic content results were very similar before and after encapsulation, showing that the encapsulation conditions (intense ultrasound and solvent exposure) did not compromise the strong antioxidant activity of curcumin.

\section{Acknowledgements}

Authors thank to Conselho Nacional de Pesquisa (CNPq), CAPES and Fundação Araucária for the financial support and scholarships.

\section{References}

1. Aggarwal, B. B., Kumar, A., \& Bharti, A. C. (2003). Anticancer potential of curcumin: preclinical and clinical studies. Anticancer Research, 23(1A), 363-398. PMid:12680238.

2. Aggarwal, B. B., Sundaram, C., Malani, N., \& Ichikawa, H. (2007). Curcumin: the Indian solid gold. Advances in Experimental Medicine and Biology, 595(1), 1-75. http:// dx.doi.org/10.1007/978-0-387-46401-5_1. PMid:17569205.

3. Ak, T., \& Gülçin, I. (2008). Antioxidant and radical scavenging properties of curcumin. Chemico-Biological Interactions, 174(1), 27-37. http://dx.doi.org/10.1016/j.cbi.2008.05.003. PMid: 18547552.

4. Gilda, S., Kanitkar, M., Bhonde, R., \& Paradkar, A. (2010). Activity of water-soluble turmeric extract using hydrophilic excipients. LWT - Food Science and Technology, 43(1), 59-66. http://dx.doi.org/10.1016/j.lwt.2009.07.004.

5. Eybl, V., Kotyzova, D., \& Koutensky, J. (2006). Comparative study of natural antioxidants - curcumin, resveratrol and melatonin - in cadmium-induced oxidative damage in mice. Toxicology, 225(2-3), 150-156. http://dx.doi.org/10.1016/j. tox.2006.05.011. PMid:16806632.

6. Wright, J. S. (2002). Predicting the antioxidant activity of curcumin and curcuminoids. Journal of Molecular Structure 
THEOCHEM, 591(1-3), 207-217. http://dx.doi.org/10.1016/ S0166-1280(02)00242-7.

7. Priyadarsini, K. I., Maity, D. K., Naik, G. H., Kumar, M. S., Unnikrishnan, M. K., Satav, J. G., \& Mohan, H. (2003). Role of phenolic $\mathrm{O}-\mathrm{H}$ and methylene hydrogen on the free radical reactions and antioxidant activity of curcumin. Free Radical Biology \& Medicine, 35(5), 475-484. http://dx.doi.org/10.1016/ S0891-5849(03)00325-3. PMid:12927597.

8. Galano, A., Álvarez-Diduk, R., Ramírez-Silva, M. T., Alarcón-Ángeles, G., \& Rojas-Hernández, A. (2009). Role of the reacting free radicals on the antioxidant mechanism of curcumin. Chemical Physics, 363(1-3), 13-23. http://dx.doi. org/10.1016/j.chemphys.2009.07.003.

9. Feng, J.-Y., \& Liu, Z.-Q. (2009). Phenolic and enolic hydroxyl groups in curcumin: which plays the major role in scavenging radicals? Journal of Agricultural and Food Chemistry, 57(22), 11041-11046. http://dx.doi.org/10.1021/jf902244g. PMid:19736944.

10. Paramera, E. I., Konteles, S. J., \& Karathanos, V. T. (2011). Microencapsulation of curcumin in cells of Saccharomyces cerevisiae. Food Chemistry, 125(1), 892-902. http://dx.doi. org/10.1016/j.foodchem.2010.09.063.

11. Rocha, B. A., Gonçalves, O. H., Leimann, F. V., Rebecca, E. S. W., Silva-Buzanello, R. A., Filho, L. C., Araújo, P. H. H., Cuman, R. K. N., \& Bersani-Amado, C. A. (2014). Curcumin encapsulated in poly-L-lactic acid improves its anti-inflammatory efficacy in vivo. Advancement in Medicinal Plant Research, 2(4), 62-73.

12. Staff, R. H., Schaeffel, D., Turshatov, A., Donadio, D., Butt, H.-J., Landfester, K., Koynov, K., \& Crespy, D. (2013). Particle formation in the emulsion-solvent evaporation process. Small, 9(20), 3514-3522. http://dx.doi.org/10.1002/smll.201300372. PMid:23606602.

13. Silva-Buzanello, R. A., Ferro, A. C., Bona, E., Cardozo-Filho, L., Araújo, P. H. H., Leimann, F. V., \& Gonçalves, O. H. (2015). Validation of an Ultraviolet-visible (UV-Vis) technique for the quantitative determination of curcumin in poly(l-lactic acid) nanoparticles. Food Chemistry, 172(1), 99-104. http:// dx.doi.org/10.1016/j.foodchem.2014.09.016. PMid:25442529.

14. Bendix, D. (1998). Chemical synthesis of polylactide and its copolymers for medical applications. Polymer Degradation \& Stability, 59(1-3), 129-135. http://dx.doi.org/10.1016/S01413910(97)00149-3

15. Leimann, F. V., Cardozo, L., Sayer, C., \& Araújo, P. H. H. (2013). Poly(3-hydroxybutyrate-co-3- hydroxyvalerate) nanoparticles prepared by a miniemulsion/solvent evaporation technique. Effect of PHBV molar mass and concentration. Brazilian Journal of Chemical Engineering, 30(2), 369-377. http://dx.doi.org/10.1590/S0104-66322013000200014.

16. Reimers, J. L., \& Schork, F. J. (1996). Predominant droplet nucleation in emulsion polymerization. Journal of Applied Polymer Science, 60(1), 251-262. http://dx.doi.org/10.1002/ (SICI)1097-4628(19960411)60:2<251::AID-APP13>3.0.CO;2-8.

17. Garlotta, D. (2002). A literature review of poly(lactic acid). Journal of Polymers and the Environment, 9(2), 63-84. http:// dx.doi.org/10.1023/A:1020200822435.

18. Prado, A. C. P., Aragão, A. M., Fett, R., \& Block, J. M. (2009). Antioxidant properties of Pecan nut [Carya illinoinensis (Wangenh.) C. Koch] shell infusion. Grasas y Aceites, 60(4), 330-335. http://dx.doi.org/10.3989/gya.107708.

19. Re, R., Pellegrini, N., Proteggente, A., Pannala, A., Yang, M., \& Rice-Evans, C. (1999). Antioxidant activity applying an improved ABTS radical cation decolorization assay. Free Radical Biology \& Medicine, 26(9-10), 1231-1237. http:// dx.doi.org/10.1016/S0891-5849(98)00315-3. PMid:10381194.
20. Matthäus, B. (2002). Antioxidant activity of extracts obtained from residues of different oilseeds. Journal of Agricultural and Food Chemistry, 50(12), 3444-3452. http://dx.doi.org/10.1021/ jf011440s. PMid:12033809.

21. Paramera, E. I., Konteles, S. J., \& Karathanos, V. T. (2011). Stability and release properties of curcumin encapsulated in Saccharomyces cerevisiae, $\beta$-cyclodextrin and modified starch. Food Chemistry, 125(3), 913-922. http://dx.doi.org/10.1016/j. foodchem.2010.09.071.

22. Wang, Y., Lu, Z., Lv, F., \& Bie, X. (2009). Study on microencapsulation of curcumin pigments by spray drying. European Food Research and Technology, 229(3), 391-396. http://dx.doi.org/10.1007/s00217-009-1064-6.

23. Patel, A., Hu, Y., Tiwari, J. K., \& Velikov, K. P. (2010). Synthesis and characterisation of zein-curcumin colloidal particles. Soft Matter, 6(1), 6192-6199. http://dx.doi.org/10.1039/c0sm00800a.

24. Yallapu, M. M., Jaggi, M., \& Chauhan, S. C. (2010). Betacyclodextrin-curcumin self-assembly enhances curcumin delivery in prostate cancer cells. Colloids and Surfaces. B, Biointerfaces, 79(1), 113-125. http://dx.doi.org/10.1016/j. colsurfb.2010.03.039. PMid:20456930.

25. Yallapu, M. M., Gupta, B. K., Jaggi, M., \& Chauhan, S. C. (2010). Fabrication of curcumin encapsulated PLGA nanoparticles for improved therapeutic effects in metastatic cancer cells. Journal of Colloid and Interface Science, 351(1), 19-29. http://dx.doi. org/10.1016/j.jcis.2010.05.022. PMid:20627257.

26. Dandekar, P. P., Jain, R., Patil, S., Dhumal, R., Tiwari, D., Sharma, S., Vanage, G., \& Patravale, V. (2010). Curcuminloaded hydrogel nanoparticles: Application in anti-malarial therapy and toxicological evaluation. Journal of Pharmaceutical Sciences, 99(12), 4992-5010. http://dx.doi.org/10.1002/ jps.22191. PMid:20821383.

27. Sharma, M., Sharma, V., Panda, A. K., \& Majumdar, D. K. (2011). Development of enteric submicron particle formulation of papain for oral delivery. International Journal of Nanomedicine, 6(1), 2097-2111. PMid:22114474.

28. Lu, X., \& Weiss, R. A. (1992). Relationship between the glass transition temperature and the interaction parameter of miscible binary polymer blends. Macromolecules, 25(12), 3242-3246. http://dx.doi.org/10.1021/ma00038a033.

29. Silverstein, R. M., Webster, F. X., Kiemle, D., \& Bryce, D. L. (2014). The spectrometric identification of organic compounds. New York: John Wiley \& Sons.

30. Cavallaro, G., La Manna, G., Liveri, V. T. T., Aliotta, F., \& Fontanella, M. E. (1995). structural investigation of water/ lecithin/cyclohexane microemulsions by FT-IR spectroscopy. Journal of Colloid and Interface Science, 176(2), 281-285. http://dx.doi.org/10.1006/jcis.1995.9966.

31. Peres, L. B., Peres, L. B., Araújo, P. H. H., Sayer, C., \& Gonçalves, O. H. (2015). Preparation of PLLA/PMMA and PLLA/PS binary blend nanoparticles by incorporation of PLLA in methyl methacrylate or styrene miniemulsion homopolymerization. Polímeros: Ciência e Tecnologia, 25(1), 23-28. http://dx.doi.org/10.1590/0104-1428.1707.

32. Eguiburu, J. L., Iruin, J. J., Fernandez-Berridi, M. J., \& San Román, J. (1998). Blends of amorphous and crystalline polylactides with poly (methyl methacrylate) and poly (methyl acrylate): a miscibility study. Polymer, 39(26), 6891-6897. http://dx.doi.org/10.1016/S0032-3861(98)00182-7.

33. Reddy, A. C. P., \& Lokesh, B. R. (1994). Studies on the inhibitory effects of curcumin and eugenol on the formation of reactive oxygen species and the oxidation of ferrous iron. Molecular and Cellular Biochemistry, 137(1), 1-8. http:// dx.doi.org/10.1007/BF00926033. PMid:7845373.

34. Sreejayan, N., \& Rao, M. N. (1994). Curcuminoids as potent inhibitors of lipid peroxidation. The Journal of Pharmacy 
and Pharmacology, 46(12), 1013-1016. http://dx.doi. org/10.1111/j.2042-7158.1994.tb03258.x. PMid:7714712.

35. Jovanovic, S. V., Steenken, S., Boone, C. W., \& Simic, M. G. (1999). H-atom transfer is a preferred antioxidant mechanism of curcumin. Journal of the American Chemical Society, 121(41), 9677-9681. http://dx.doi.org/10.1021/ja991446m.

36. Zhu, Q. Y., Hackman, R. M., Ensunsa, J. L., Holt, R. R., \& Keen, C. L. (2002). Antioxidative activities of oolong tea. Journal of Agricultural and Food Chemistry, 50(23), 69296934. http://dx.doi.org/10.1021/jf0206163. PMid:12405799.

37. Pan, Y., Tikekar, R. V., \& Nitin, N. (2013). Effect of antioxidant properties of lecithin emulsifier on oxidative stability of encapsulated bioactive compounds. International Journal of Pharmaceutics, 450(1-2), 129-137. http://dx.doi.org/10.1016/j. ijpharm.2013.04.038. PMid:23618963.

38. Wang, Y., Lu, Z., Wu, H., \& Lv, F. (2009). Study on the antibiotic activity of microcapsule curcumin against foodborne pathogens. International Journal of Food Microbiology, 136(1), 71-74. http://dx.doi.org/10.1016/j.ijfoodmicro.2009.09.001. PMid:19775769.

Received: June 03, 2015

Revised: Nov. 01, 2015

Accepted: Feb. 12, 2016 